\title{
Thermoplastic Polyolefins as Formaldehyde Free Binders in Highly Filled Lignocellulosic Panel Boards: Using Glycerine as a Processing Aid in Kenaf Fiber Polypropylene Boards
}

\author{
Anand Ramesh Sanadi**, Daniel Caulfield ${ }^{\mathrm{b}}$ \\ ${ }^{a}$ Research Scientist, Forest \& Landscape, Faculty of Life Sciences, University of Copenhagen, \\ Rolighedsvej 23, 1958 Frederiksberg, Denmark \\ ${ }^{\mathrm{b}}$ Consultant, 14 Quinn Circle, Madison - WI, USA
}

Received: October 1, 2008; Accepted: November 25, 2008

\begin{abstract}
A new technique was developed to make highly loaded (up to $95 \%$ ) formaldehyde free natural fiber boards. The purpose of the paper is to report a broad study on $85 \%$ kenaf boards using linear thermoplastic polymers as the binder in preparing the boards to determine if these materials have potential in commercial applications by comparing them to other commercial materials. In these materials, linear thermoplastic polymer chains act as an adhesive and the product resembles a typical wood based panel (e.g., phenol formaldehyde fiber board). The process involved the use of small amount of glycerine in the fiber to enhance processibility in a thermo-kinetic mixer followed by hot pressing. In this paper, we report the properties of $85 \%$ by weight kenaf fiber boards using polypropylene as the adhesive. A maleated polypropylene was used to improve the adhesion and stress transfer between the adhesive and kenaf fiber. The addition of $2 \%$ by weight of glycerine based on the dry weight of kenaf fiber resulted in the best properties of the boards. Differential scanning calorimetric studies suggested that the glycerine had a little effect on the percent crystallinity of the matrix. Dynamic mechanical tests of the $85 \%$ boards showed some differences compared to conventional $60 \%$ by weight kenaf-PP composites. The $85 \%$ kenaf boards had a flexural strength of 75 $\mathrm{MPa}$ and a flexural modulus of $6.8 \mathrm{GPa}$ with a specific gravity of 1.24 . These properties are comparable to standard formaldehyde free high density hardboards with flexural strengths of $48.3 \mathrm{MPa}$ and flexural modulus of $5.5 \mathrm{GPa}$, and a specific gravity of 1.28. This paper gives a broad overview of an initial study of these new materials.
\end{abstract}

Keywords: wood panel boards, hard boards, wood composites, binderless hardboards, kenaf boards, lignin plasticization

\section{Introduction}

Wood based fiberboards are used extensively throughout the world in both the building and furniture industries. There are concerns regarding the use of toxic chemicals such as formaldehyde, phenols and isocynates, and there is interest in developing new fiberboards without the use these chemicals. Research is ongoing in the development of fiberboards from various sources of fiber ${ }^{1}$ and also in studying the plasticization of lignin to obtain a deeper understating of board properties $^{2}$. There has also been research into the use of powder kenaf core in binderless boards ${ }^{3,4}$.

The use of natural fibers and wood fibers as fillers and reinforcements in thermoplastics has increased recently, with considerable growth in the automotive and building materials sector. In the United States the building and construction industry is the predominant consumer of these materials, and this market is growing in Europe $e^{5,6}$. In Brazil, fibers such as sisal have great potential ${ }^{7,8}$, and are used in the automotive sector and have great potential in the building and construction industry. There have also been studies of using non-wood natural fibers as reinforcements in polyester and other thermoset polymers $^{9}$. A recent literature review covers a variety of aspects of cellulose based composites ${ }^{10}$.

A new technique was developed that allowed very high fiber loading, up to $95 \%$ by weight of kenaf fibers in polyolefins ${ }^{11}$. This technique involved the use of glycerine during the compounding of the composite which permits high fiber loading in the polyolefins, without thermal degradation of the fiber. Initially we modeled the system as a typical natural fiber composites in which the matrix is the continuous phase and reinforced with kenaf fibers ${ }^{11}$. However, additional experiments and a recent review of the work along with additional scanning electron microscopy have given us new insights into this material. It appears that linear polyolefin chains act more as

*e-mail: anrs@life.ku.dk

Part of this work was done when the author (ARS) was at the University of Wisconsin, Madison, USA a binder and adhesive between the kenaf fibers, similar to traditional wood composites, such as particle and fiber boards with urea or phenol formaldehyde adhesives. In these materials, typical thermoplastic polymers have been used as binding agents in natural fiber boards.

At present, in commercial applications, the amount of fibers or fillers being used is generally limited to about $60 \%$ and below by weight of fibers in the thermoplastics. In these systems, these materials are true fiber reinforced polymers since the polymer is in a continuous phase with fibers or fillers dispersed in the material. There are applications where higher lignocellulosic content thermoplastics are used commercially. For example, products from Strandex Corporation (Madison, WI, USA) are directly extruded using $70 \%$ wood fillers in plastics. However, their process is exclusive to extrusion, where higher viscosities are permissible. Also, to achieve higher performance, the process must also include thermosets (unsaturated binding agents- e.g. isocyanates, polyurethanes) to help in binding the system together ${ }^{12}$. We are not aware of any study or report on highly filled natural fiber composites with fairly high aspect ratios, at loadings greater than $75 \%$. The aspect ratio of the kenaf fibers we have used can be higher than $100^{13}$.

The inherent polar and hydrophilic nature of the lignocellulosic fibers and the non-polar characteristics of the polyolefins create difficulties in compounding and result in composites with low stress transfer efficiency. Proper selection of coupling agents and other additives are necessary in improving the interaction, adhesion and stress transfer ${ }^{14-18}$. The use of maleated polyolefins as compatibilizers/coupling agents in lignocellulosic-polyolefin systems is well established ${ }^{17,19}$.

The purpose of the paper is to report a broad study on $85 \%$ kenaf boards using linear polymers (PP/MAPP) as the binder in 
preparing the boards to determine if these materials have potential in commercial applications by comparing them to other commercial materials. The amount of glycerine used to make these boards was optimized for the best properties. Differential scanning calorimeter (DSC) studies were conducted to determine if glycerine had any effect on the crystallinity of the PP based binder system. Dynamic mechanical analysis (DMA) was used to compare the low and high temperature properties to typical $60 \%$ by weight kenaf-PP injection molded composites. Flexural properties were compared with $60 \%$ kenaf-PP composites and also with typical traditional commercially available wood based panel boards.

\section{Experimental Procedure}

Kenaf fibers, a few inches long, harvested from mature plants were obtained from Ken-Gro Corporation, Mississippi, USA. The polypropylene was the homopolymer- Fortilene 1602 (Solvay Polymers, Houston, TX, USA) with a melt flow index of $12 \mathrm{~g} / 10 \mathrm{~min}$ (manufacturers data) measured using ASTM D-1238. A maleated polypropylene, G-3002 (Eastman Chemical Products, TN, USA) was used as a coupling agent. This MAPP had about 6 wt.(\%) of maleic anhydride grafted on to the polymer chain and the $\mathrm{MW}_{\#}$ was 11,000 Daltons and $\mathrm{MW}_{\mathrm{wt}}$ was 40,000 Daltons. Glycerine (glycerol and IUPAC name: propane-1,2,3-triol) was obtained from Aldrich Chemical and had a purity of $99 \%$, and a boiling point of $290{ }^{\circ} \mathrm{C}$.

Kenaf bast fibers were cut into about $1 \mathrm{~cm}$ in length. Glycerine was added to water at about a 1:50 ratio. The amount of glycerine used varied between 1, 2 and $4 \%$ of the dry weight of kenaf fibers. The mixture was stirred and put into a typical garden spray bottle. The fibers were spread out and the mixture sprayed over the fibers, while constantly turning and moving the fibers to get uniform distribution of the glycerine. The samples were air dried for at least one week at ambient conditions prior to the next stage of preparing the boards.

The short bast fibers (85\%), MAPP (5\%) and PP (10\%) were compounded in a one-liter high intensity kinetic mixer (hence forth known as k-mixer) from Synergistics Industries Ltd., Canada, where the only source of heat is generated through the kinetic energy of rotating blades. The required weight of dry fibers (dry fiber without both moisture and glycerine taken into account) and polymers were inserted into the blender and compounded at $5000 \mathrm{rpm}$ resulting in a blade tip speed of about $30 \mathrm{~m} / \mathrm{s}$. The compounded mass was then automatically discharged at $200{ }^{\circ} \mathrm{C}$. The precise time to discharge depended on the amount of fiber and polymer, and their ratios and how hot the mixer was when the blending started. The average time of blending varied from 2 to 3 minutes with higher fiber content blends taking longer to reach $200{ }^{\circ} \mathrm{C}$. However, in this paper, data for $85 \%$ boards are the only ones reported. The compounded mass was then immediately compression molded, between flat plates, in a hot press at $190{ }^{\circ} \mathrm{C}$ for 3 minutes.

Three boards were made for each set of experiments. The specimens were stored under controlled conditions (20\% relative humidity and $32{ }^{\circ} \mathrm{C}$ ) for 3 days before testing. Four flexural specimens were cut from each of the three boards. Six specimens (two from each board) were tested for each data point. Specimen dimensions were according to the respective ASTM standards. Flexural testing was done using the ASTM 790-90 standard. The fracture surfaces of some of the tested specimen were observed using a JEOL scanning electron microscope.

A Perkin Elmer DSC was used to evaluate the crystallization and melting behaviour of the boards. The samples were first heated to $220^{\circ} \mathrm{C}$ at $20^{\circ} \mathrm{C} / \mathrm{min}$ and then held isothermally for 1 minute in a nitrogen atmosphere. The samples were then cooled at $10^{\circ} \mathrm{C} / \mathrm{min}$ to collect crystallization data, and heated again at $10^{\circ} \mathrm{C} / \mathrm{min}$ to observe the melting transition. The sample sizes were kept between 9 and $11 \mathrm{mg}$ and all tests were run under nitrogen gas. The \% crystallinity is determined as the heat of fusion of the sample relative to that of a $100 \%$ crystalline sample. The heat of fusion of pure crystalline isotactic PP is $209 \mathrm{~J} / \mathrm{g}^{20}$. Dynamic properties of the composites were measured using a Rheometrics DMTA MKIII. The samples were cut to size from the center of the boards. A single cantilever test was used for the testing with a span of $14 \mathrm{~mm}$, and sample width and depth were about $5 \mathrm{~mm}$ and $1 \mathrm{~mm}$, respectively. The deflection amplitude was $16 \mu \mathrm{m}$, frequency $1 \mathrm{~Hz}$ and the heating ramp rate was $2{ }^{\circ} \mathrm{C} / \mathrm{min}$ and strain of $0.024 \%$. Only specimen prepared using $2 \%$ by weight of glycerine were used in both DSC and DMTA analysis.

\section{Results and Discussion}

The effect of glycerine on board preparation was evaluated. It was only possible to prepare $85 \%$ by weight kenaf-PP boards without significant kenaf thermal degradation when glycerine was used. It appears that the glycerine broadens the processing window of compounding the fibers and polymer (Figure 1). The processing window is the temperature range over which the polymer has melted and is well dispersed and at the same time there is no fiber thermal degradation. There could be several reasons why the use of glycerine helped in preparing boards without kenaf fiber degradation. a) Heat developed during the compounding in the kenaf fiber is used to vaporize the glycerine present in the fiber and thereby dissipating heat and preventing the burning of the fibers; and b) Glycerine vapor may displace oxygen and reduce chances of fiber burning. The processing window could be very narrow when there is no glycerine and our control over the compounding stage was not good enough to make sample boards. The use of glycerine expands the processing window, Figure 1. The use of glycerine explains the shift of the upper end of the processing window to higher temperatures since its presence prevents the burning of the fibers.

We observed shifts in the processing window to lower temperatures when compounding typical $60 \%$ weight kenaf-PP composites while using glycerine. The use of glycerine resulted in the polymer having melted and well dispersed with fibers at temperatures of about $160{ }^{\circ} \mathrm{C}$. The normal temperature when fibers are well dispersed and polymer is molten is about $190{ }^{\circ} \mathrm{C}$. This is also true with the $85 \%$ kenaf boards, but this is hard to compare since boards without the use of glycerine could not be prepared without significant fiber thermal degradation. This is probably due to the plasticization and lubricant effect of the glycerine on the polymer and also the plasticization of the lignin and amorphous polymers present in kenaf.

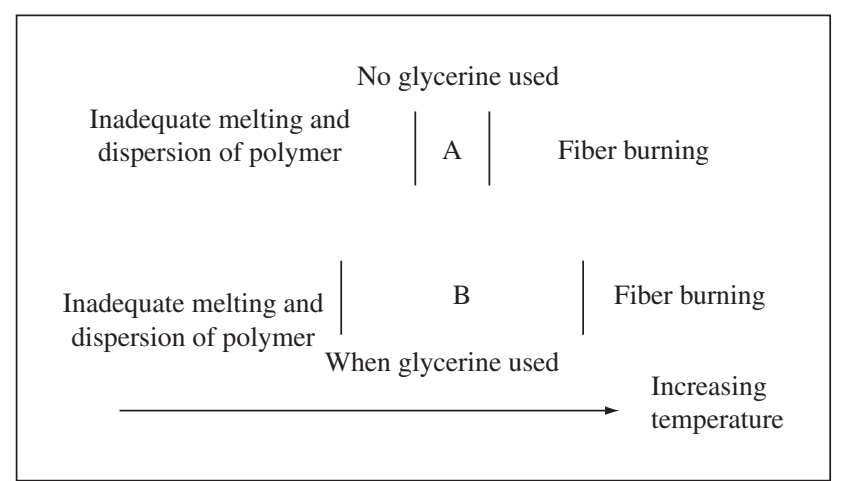

Figure 1. Schematic of processing window of fibers with and without glycerine: A) When no glycerine used, the processing window use is very narrow; and B) When glycerine was used it expanded the processing window. 
The flow of thermoplastic melts cannot be increased as desired (beyond practical limits) by raising the temperature: polymer molecular weight loss or crosslinking along with discoloration can occur due to the chemical instability of the macromolecule ${ }^{21}$. Furthermore, in the case of lignocellulosic composites, fiber thermal degradation can take place at elevated temperatures. Higher processing temperatures require additional energy and could also lead to lower molding outputs through longer cool times. Furthermore, lignocellulosic fibers thermally degrade at higher temperatures. Polymer rheology is affected by several factors including stress, strain, time, temperature and additives such as plasticizers and lubricants. Several mechanisms can affect the characteristics of the polymer and thereby the compounding and blending of plastics, apart from the different mechanisms under which those plasticizers/ lubricants function ${ }^{21-23}$. It is well known that sorption of vapors or gases by polymers can cause significant plasticization resulting in a substantial decrease in the glass transition temperature ${ }^{24}$. For example, the glass transition of PET decreased from about 80 to about $5{ }^{\circ} \mathrm{C}$ with about 0.10 mole fraction of $\mathrm{CO}_{2}$ $\operatorname{gas}^{25}$ in the polymer. The presence of solvents and stresses can also decrease the surface energy required to form a craze and/or decrease the flow stress due to plasticization at the craze tips. For example, solvent crazing of glassy polymers (e.g., polycarbonate) can create a bulk plasticization effect due to the stress-induced adsorption ${ }^{26,27}$.

In the case of wood, moisture or other plasticizers drastically affect the glass transitions of the amorphous parts (lignin and hemicellulose). Kelley, Rials and Glasser ${ }^{28}$ have studied the transitions for wood. The glass transition temperature $\left(\mathrm{T}_{\mathrm{g}}\right)$ of lignin can drop to about $70{ }^{\circ} \mathrm{C}$ in the presence of about $15 \%$ moisture, while that of hemicellulose can go below $0{ }^{\circ} \mathrm{C}$ at this moisture content. They also found that strong H-bonding solvents, such as formamide, could be effective plasticizers for the lignin and hemicellulose than weaker H-bonding solvents. Recent work has studied the plasticizing effect of various molecules on lignin ${ }^{2}$ - unfortunately the effect of glycerine was not studied. Furthermore, the structure of the lignin can also alter the molecular transitions of the lignin ${ }^{29}$. Ralph ${ }^{30}$ mentioned that kenaf has an unusual type of lignin, with extensive side chains that are acetylated, and this will change the transition of lignin compared to wood lignins. The transition of hemicelluloses are also affected by the type and amount of the plasticizer. Olsson and Salmen ${ }^{31}$ have studied the transition behavior with respect to the amount of moisture.

An interesting point to note is that the glycerine plasticizes the amorphous components (lignin and hemicellulose) of the kenaf fibers by breaking some of the H-bonds present. Kenaf fibers have a significant amount of amorphous lignin (15-19\%) and amorphous hemicellulose (22-23\%) along with crystalline cellulose (44-57\%) $)^{13,32}$. The amorphous content then accounts for about $40 \%$ of the material in kenaf. A highly filled kenaf-PP board can thus have a significant amount of amorphous polymers in the composite. Thus in the kenaf fiber the amorphous component (lignin and hemicellulose) can vary from 43 to about $56 \%$. Since the boiling point of glycerine is very high, the plasticization can occur well above the boiling point of water, and during the compounding of the kenaf boards. The presence of glycerine may permit the kenaf fibers to deform without extensive breaking during the high intensity of mixing also during the hot press cycle. It is not inconceivable that the lignin can be plasticized to make binderless fiberboards and research is being done in this area to understand the plasticization process ${ }^{33}$. This along with understanding the plasticization process of hemicelluloses ${ }^{31}$ could help in developing a new generation of panel boards using thermoplastic (linear) polymers as binders.

The effect of the amount of glycerine in the fibers also is important (Table 1). Sufficient glycerine is needed to prevent thermal degradation and also help plasticize the amorphous material at high temperatures. A $2 \%$ by weight of glycerine based on the dry weight of the fiber gave the best results. At higher glycerine loadings there was a drop in both strength and modulus.

Figure 2 shows scanning electron microscopy of the fracture surfaces $85 \%$ kenaf fiber-PP/MAPP boards (using 2\% glycerine) showed that the bonding between the fiber and polymer appears to be good. The orientation of the fibers seemed random (Figure 2a) and this makes sense when one compression molds the blended mass that

Table 1. Effect of amount of glycerine based on dry weight of fiber, on composite properties. (standard deviations in brackets).

\begin{tabular}{ccccc}
\hline $\begin{array}{c}\text { Kenaf } \\
\text { content }\end{array}$ & $\begin{array}{c}\text { Glycerine } \\
(\%)\end{array}$ & $\begin{array}{c}\text { Flexural } \\
\text { strength } \\
(\mathrm{MPa})\end{array}$ & $\begin{array}{c}\text { Flexural } \\
\text { modulus } \\
(\mathrm{GPa})\end{array}$ & $\begin{array}{c}\text { Specific } \\
\text { gravity }\end{array}$ \\
\hline 85 & 1 & $68(7)$ & $6.2(0.4)$ & 1.235 \\
85 & 2 & $75(9)$ & $6.8(0.5)$ & 1.234 \\
85 & 4 & $64(9)$ & $6.1(0.6)$ & 1.241 \\
\hline
\end{tabular}

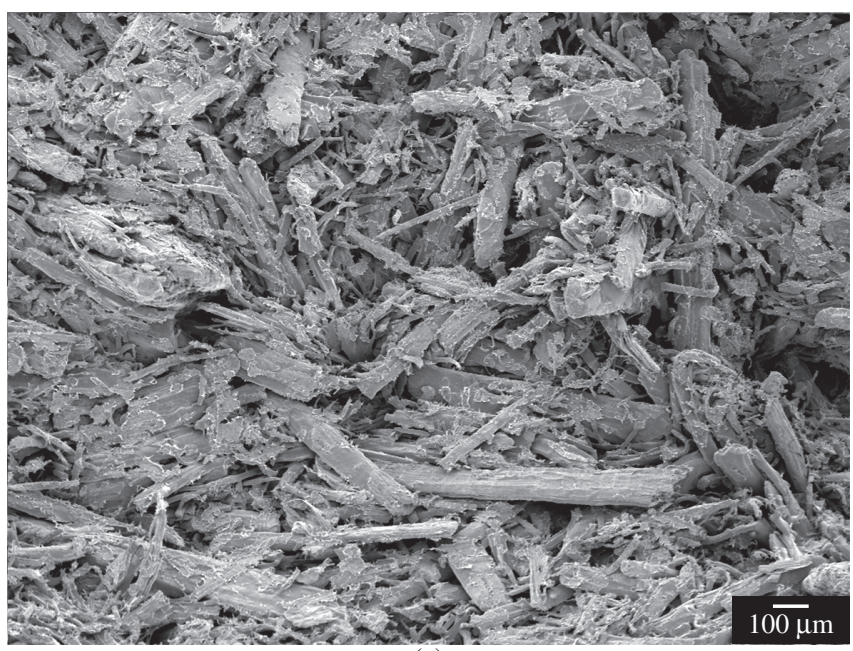

(a)

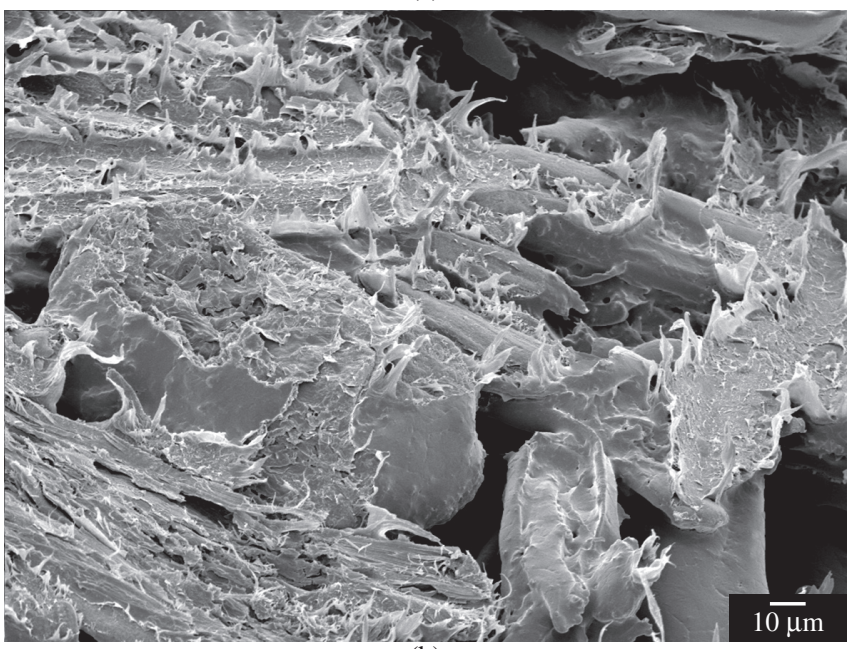

(b)

Figure 2. a) Shows the fracture surface of an $85 \%$ by weight kenaf-PP/MAPP board. (Note several fibers appear well bonded and the fibers have themselves between torn apart.) Some voids can also be seen; and b) A close-up of an $85 \%$ weight composite shows polymer adhering to the fiber surface. This indicates good bonding between the fiber and the PP/MAPP. 
comes out of the thermokinetic mixer. Quite a few voids can also be seen indicating that the PP/MAPP acts as an adhesive between the fibers rather than as a continuous mass as in the case of a typical fiber reinforced composite. This is in opposition to typical kenaf-PP composites reported (prepared by extrusion and injection molding) where there are practically no voids. Furthermore, when composites are injection molded as in earlier studies ${ }^{17,19,34}$, the fibers are preferentially aligned in the direction of the molding axis. The interface between the PP/MAPP and the fiber surface appears to be good. Figure $2 b$ shows a fracture surface where one can see polymer adhering to the fiber surface which indicates that the adhesion is good.

An $85 \%$ by weight kenaf board has a theoretical kenaf volume fraction of about $78 \%$ assuming fiber specific gravity of 1.4 . It is theoretically not possible to have "true" fiber composite (i.e., with a continuous matrix phase with embedded fibers and with no voids) with a fiber volume fraction of $78 \%$ when the fibers are randomly distributed. Thus the polymer molecules act as binders in the $85 \%$ kenaf boards and this is similar in function to phenol formaldehyde in typical wood panel boards.

DSC results indicate there is a little difference in the onset and peak crystallization and the melting temperatures between the kenaf composites (Table 2). The percent crystallinity of polymer present in the $85 \%$ boards (PP/MAPP mixture) was however marginally lower than of a typical $60 \%$ kenaf-PP/MAPP injection molded fiber reinforced composite. These data were from an average taken from two samples. The value of the crystallization enthalpy for pure PP was $209 \mathrm{~J} / \mathrm{g} .{ }^{20}$ There is a difference in the onset Tc and peak Tc between the pure PP and kenaf-PP composites (60\% kenaf) and boards ( $85 \%$ kenaf). It is believed that the fiber surface nucleates the crystallization of PP at higher temperatures. ${ }^{35,36}$ The $85 \%$ kenaf boards had a larger percent of MAPP ( $5 \%$ of composite weight) than $60 \%$ kenaf-PP composite $(2 \%)$ and this can also affect the amount of crystallinity being measured. The difference in crystallinity could be due to the glycerine present, but the higher MAPP content can also explain the difference. It should be noted that the $85 \%$ boards has a significantly higher surface area exposed to the PP than the $60 \%$ composites. Further studies need to be conducted to determine the primary reason.

The DMA spectra of the $85 \%$ kenaf boards (Figure 3) show some interesting features when compared to a typical $60 \%$ kenaf fiber reinforced composite that was injection molded. It should be noted that the $60 \%$ composites were injection molded, which results in significant amount of fiber alignment. This is as opposed to the compression molded $85 \%$ boards where the fibers were randomly distributed. At low temperatures, the $60 \%$ composites have a higher storage modulus (E'), which suggests a brittle material at these temperatures. However, after about $10{ }^{\circ} \mathrm{C}$, the $85 \%$ boards have a higher modulus. The difference in storage moduli become even more pronounced as the temperature increases. The softening temperature of the $85 \%$ boards is also higher than the $60 \%$ composite. The lower modulus at low temperature and the higher modulus at higher temperature is an advantage of the $85 \%$ composite, since the composite is not as brittle as the $60 \%$ at lower temperatures but maintains its integrity better at higher temperatures.

In terms of the loss modulus (E") spectra, two transitions can be clearly seen. The $\alpha$ transition, related to the glass-rubbery transition, is due to molecular motions associated with unrestricted amorphous $\mathrm{PP}^{37}$. The $\beta$ transition is related to the relaxation of restricted PP amorphous chains in the crystalline phase. The presence of crystals is necessary for this transition to occur ${ }^{38,39}$.

The $\beta$ transition, occurring at about 10 to $25^{\circ} \mathrm{C}$ is associated with the glassy-rubbery transition of the amorphous chains of the polymer and the $\alpha$ transition is related to the crystallites, but the relaxation occurs due to the presence of "rigid" amorphous molecules present within the crystal ${ }^{36}$. These regions disrupt the purity of the crystals and thus can be considered to be defects. The $\beta$ relaxation for the $85 \%$ composite is much wider than the $60 \%$ composite. The wider relaxation and the shift to higher temperatures generally indicate that some of the amorphous molecules are more restricted. This is possible when amorphous molecules bridge two crystals and result in higher temperatures for their glass-rubbery transition. Secondly, any amorphous molecules near the fiber surface in the $85 \%$ boards are further restricted in mobility due to interactions with the solid fiber surface since the distance between fiber surfaces is smaller (compared to $60 \%$ composite). Furthermore, since the $85 \%$ boards have a significantly higher fiber surface exposed to the polymer- the polymer molecules near the surface have restricted mobility and therefore result in higher $\beta$ relaxation temperatures.

Table 3 compares the flexural strength and modulus of kenaf-PP boards (using $2 \%$ glycerine) with those of commercially available conventional wood based boards. Data of the wood based panel products were from the Wood Handbook ${ }^{40}$. The strength of the kenaf-PP

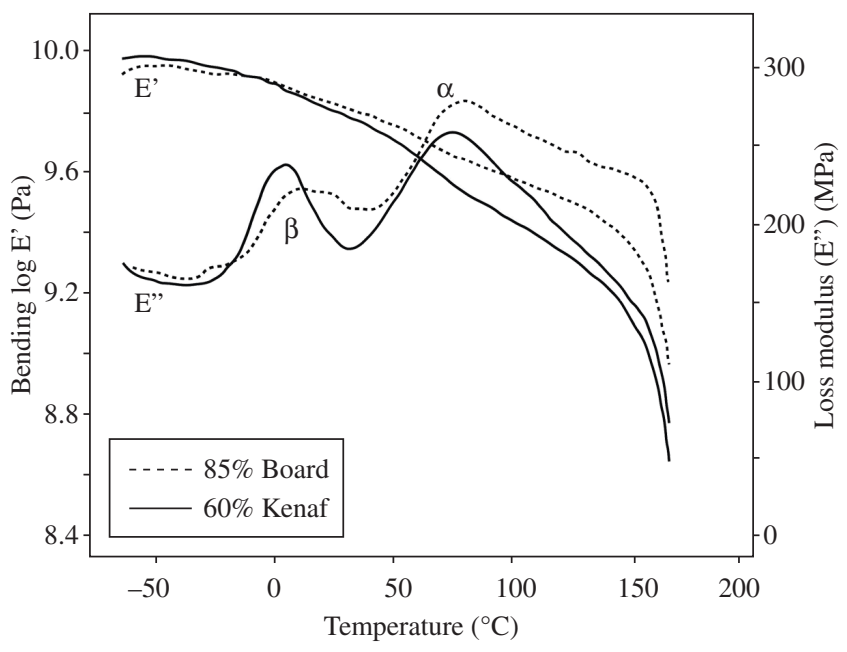

Figure 3. Storage and loss modulus of an $85 \%$ fiber filled composite compared to injection molded $60 \%$ fiber filled composite.

Table 2. Crystallinity data of the plastic matrix for kenaf composites. (MAPP was used as the compatibilizer/ coupling agent; Pure PP crystals- crystallization enthalpy $=209 \mathrm{~J} / \mathrm{g}){ }^{20}$

\begin{tabular}{lcccc}
\hline \multicolumn{1}{c}{ Composite type } & Tc $\left({ }^{\circ} \mathrm{C}\right)$ peak & Onset Tc $\left({ }^{\circ} \mathrm{C}\right)$ & Tm $\left({ }^{\circ} \mathrm{C}\right)$ peak & $\%$ crystallinity \\
\hline PP - 100\% & 110.63 & 116.33 & 161.70 & 44.5 \\
60 - PP/ MAPP (injection molded) & 122.96 & 127.12 & 163.67 & 44.1 \\
$85 \%$ - PP/MAPP (compression molded) & 122.96 & 127.51 & 163.70 & 42.6 \\
\hline
\end{tabular}


boards was significantly higher than the standard high density hardboards and in the same range as tempered hardboards. The density of the kenaf-PP boards were in the same range as hardboards. The special densified hardboards had both higher properties and specific gravity as compared to the kenaf-PP composites. Due to the presence of the linear polymer binders, the wet mechanical properties of the kenaf-PP boards are expected to be higher than the hardboards, although we did not measure these properties for this study. Another advantage is that very complex shaped (Figure 4) can be made during the pressing cycle that may have implications in large volume indoor furniture applications since it reduces cost of the final product. In this case, a special mold with ribs was used instead of hot pressing between flat plates.

Both strength and modulus of the $85 \%$ boards are lower than $60 \%$ (injection molded) kenaf fiber reinforced PP composites (Table 3) ${ }^{19}$ This is not surprising since the $85 \%$ boards have randomly oriented fibers and the boards are hot pressed. In the case of the $60 \%$ composites the specimens were injection molded and tested along the direction of mold flow. In this injection molding process, the fibers align in the direction of the mold flow, resulting in high strengths and moduli which are higher than the randomly fiber oriented $85 \%$ boards.

\section{Conclusions}

A new technique of using glycerine to facilitate the preparation of highly filled natural fiber boards in PP was developed. Glycerine, to the amount of $2 \%$ by weight of dry kenaf fibers resulted in the better properties than 1 and $4 \%$ by weight glycerine. From SEM micrographs and visual observation the fibers appear to be randomly oriented in the boards. The PP acts like an adhesive that binds the fibers together similar to the way conventional formaldehyde based

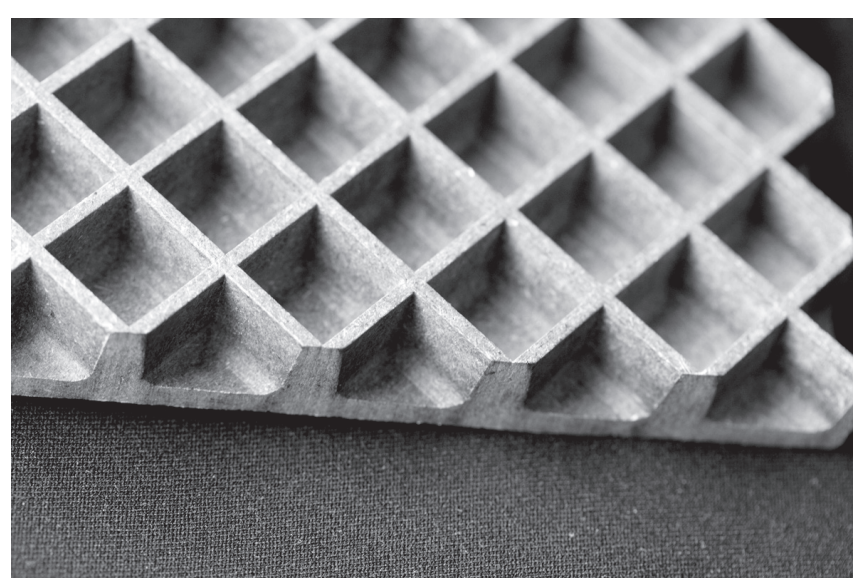

Figure 4. Photograph of a complex shape of an $85 \%$ kenaf-PP/MAPP board. The total depth of the board was about $1.4 \mathrm{~cm}$ and the grid height was $1 \mathrm{~cm}$ showing how complex shapes can be molded directly after the blending cycle. resins acts as in conventional wood based composites. DSC data indicate there is a small difference in the crystallinity of the PP when using glycerine, but this difference could be because of the high percent of low molecular eight MAPP (5\%) used in preparing these boards. DMA data indicate that the $85 \%$ boards have much higher integrity at higher temperatures as compared to typical $60 \%$ kenaf-PP injection molded composites. The flexural strength, flexural modulus and specific gravity of the $85 \%$ boards compare well with high density hardboards. One advantage of the $85 \%$ kenaf-PP boards is that complex shapes can be molded during the hot press cycle. Furthermore due to the use of the thermoplastic PP, any excess material in the production cycle can be chipped and reused during the blending stage. These materials also have the advantage of being recyclable due to the use of PP. However, at this stage further studies need to be conducted on these new materials to evaluate properties such as toughness, creep, etc to get a better idea of the potential of these $85 \%$ boards.

\section{Acknowledgements}

The author would like to acknowledge the help of Craig Clemons who dusted some of the rust of my knowledge. Finally the author is grateful to Claus Felby in helping provide the funds to complete this study. The author also thanks Jan Bach Kristensen for help with the photographs.

\section{References}

1. Hunt J, Supan K. Binderless fiberboard: comparison of fiber from recycled corrugated conatiners and refined small-diametr whole treetops. Forest Products Journal 2006; 56(7/8):69-74.

2. Bouajila J, Limare A, Joly C, Dole P. Lignin plasticization to improve binderless fiberboard mechanical properties. Polymer Engineering and Science 2005; 45 (6):809-816.

3. Okuda N, Sato M. Water resistance properties of kenaf core binderless boards. Journal of Wood Science 2006; 52(5):422-428.

4. Okuda N, Sato M. Bond durability of kenaf core binderless boards II: outdoor exposure test. Journal of Wood Science 2008; 54(1):36-44.

5. Anon. WPCs extend service life for Venetian structures. Plastics Additives \& Compounding 2008; April 23, http://www.addcomp.com/articles/green/ product/080423_technoplast.html.

6. Anon. Outdoor living space drives growth in wood-plastic composites. Plastics Additives \& Compounding July/August 2008: 20-25, http://www. addcomp.com/articles/wood/features/080701_woodplastics.pdf.

7. Mattoso LHC, Ferreira FC, Curvelo AAS. Sisal fiber: morphology and applications in polymer composites In: A Leao, FX Carvalho, E Frollini (eds). Lignocellulosic-plastic composites. São Paulo: USP and UNESP; 1997.

8. Satyanarayana KG, Guimaraes JL, Wypych F. Studies on lignocellulosic fibers of Brazil. Part I: Source, production, morphology, properties and applications. Composites Part A: Applied Science and Manufacturing 2007; 38(7):1694-1709.

Table 3. comparison of flexural properties of commercial available hardboards (data from Wood Handbook) ${ }^{40}$ with Data on $85 \%$ Kenaf-PP boards. Data on $60 \%$ kenaf-PP samples from Sanadi, et al. (1995). ${ }^{19}$

\begin{tabular}{lccc}
\hline \multicolumn{1}{c}{ Type of Board } & Flexural modulus (GPa) & Flexural strength (MPa) & Specific gravity \\
\hline Standard high density hardboard & 5.5 & 48.3 & 1.28 \\
Tempered hardboard & 7.5 & 69 & 1.28 \\
Special densified hardboard & 8.6 & 86 & 1.44 \\
$60 \%$ injection molded Kenaf-PP composites & 10.1 & 110 & 1.13 \\
$85 \%$ kenaf-PP boards from this work & 6.8 & 75 & 1.24 \\
\hline
\end{tabular}


9. Sanadi AR, Prasad SV, and Rohatgi PK. Sunhemp Fiber-Reinforced Polyester.1. Analysis of Tensile and Impact Properties. Journal of Materials Science 1986; 21(12):4299-4304.

10. John MJ, Thomas S. Biofibres and biocomposites. Carbohydrate Polymers 2008; 71(3):343-364.

11. Sanadi AR, Caulfield DF. Highly filled formaldehyde-free natural fiber polyproylene composites. In: Proceedings of the Third International Symposium on Natural Fibers and Composites- ISNAPOL 2000; 14-5-2000; Sao Pedro, SP, Brazil; 2000.

12. Laver, L. Extruded synthetic wood composition and method for making same. USA Patent No. 5,516,472; 1996.

13. Ververis C, Georghiou K, Christodoulakis N, Santas P, and Santas R. Fiber dimensions, lignin and cellulose content of various plant materials and their suitability for paper production. Industrial Crops and Products 2004; 19(3):245-254.

14. Felix JM, Gatenholm P. The Nature of Adhesion in Composites of Modified Cellulose Fibers and Polypropylene. Journal of Applied Polymer Science 1991; 42(3):609-620.

15. Gauthier R, Joly C, Coupas AC, Gauthier H, Escoubes M. Interfaces in polyolefin/cellulosic fiber composites: Chemical coupling, morphology, correlation with adhesion and aging in moisture. Polymer Composites 1998; 19(3):287-300.

16. Nachtigall SMB, Cerveira GS, Rosa SML. New polymeric-coupling agent for polypropylene/wood-flour composites. Polymer Testing 2007; 26(5):619-628.

17. Sanadi AR, Young RA, Clemons C, Rowell RM. Recycled Newspaper Fibers As Reinforcing Fillers in Thermoplastics.1. Analysis of Tensile and Impact Properties in Polypropylene. Journal of Reinforced Plastics and Composites 1994; 13(1):54-67.

18. Sebe G. Chemical Functionalization of Lignocellulosic Polymers for the Control of Interfacial Adhesion in Wood and Biofiber- Plastic Composites. In: 9th International Conference on Wood and Biofiber Plastic Composites. Forest Products Society. [cited 2007 May 21]. Available from: http://www. forestprod.org/woodfiber07sebe.pdf. Electronic Citation

19. Sanadi AR, Caulfield DF, Jacobson RE, Rowell RM. Renewable Agricultural Fibers As Reinforcing Fillers in Plastics - MechanicalProperties of Kenaf Fiber-Polypropylene Composites. Industrial \& Engineering Chemistry Research 1995; 34(5):1889-1896.

20. Wunderlich B. Macromolecular Physics. Crystal Structure, Morphology, Defects. New York: Academic Press; 1983.

21. Meier L. Plasticizers. In: Plastic Additives.Munich, Germany: Hanser Publishers; 1990.

22. Grossman RF. Lubricants. In: Thermoplastic Polymer Additives, Theory and Practice. New York, USA: Marcel Dekker Inc.; 1988.

23. Riedel T. Lubricants and Related Additives. In Plastic Additives. Munich Germany: Hanser Publishers; 1990.
24. Bernier GA, Kambour RP. The Role of Organic Agents in the Stress Crazing and Cracking of Poly(2,6-dimethyl-1,4-phenylene oixde). Macromolecules 1968; 1(5):393-400.

25. Baldwin DF, Gustafson DE, Suh SP, Shimbo M. Annual Technical Conference- ANTEC. Conference Proceedings Plastics Engineering; 9-5-1993. Society of Plastics Engineers; 1993.

26. Kambour RP, Gruner CL, and Romagosa EE. Bisphenol-A Polycarbonate Immersed in Organic Media - Swelling and Response to Stress. Macromolecules. 1974; 7(2):248-253.

27. Kefalas VA. Solvent Crazing As A Stress-Induced Surface-Adsorption and Bulk Plasticization Effect. Journal of Applied Polymer Science 1995; 58(4):711-717.

28. Kelley SS, Rials TG, Glasser WG. Relaxation Behavior of the Amorphous Components of Wood. Journal of Materials Science 1987; 22(2):617-624.

29. Olsson AM. Salmen L. The effect of lignin composition on the viscoelastic properties of wood. Nordic Pulp and Paper Research Journal 1997; 12(3): 140-144.

30. Ralph J. An unusual lignin from kenaf. Journal of Natural Products 1996; 59(4):341-342.

31. Olsson AM. Salmen L. The softening behavior of hemicelluloses related to moisture In: Gatenholm P. and Tenkanen M. (editors). ACS Symposium Series 864. Hemicelluloses Science and Technology; 2004. Washinton D.C.: American Chemical Society; 2004.

32. Han JS, Rowell JS. In Paper and Composites from Agrobased Resources. In: RM Rowell, RA Young, J Rowell (eds). New York: CRC Press; 1997.

33. Bouajila J, Dole P, Joly C, Limare A. Some laws of a lignin plasticization. Journal of Applied Polymer Science 2006; 102(2):1445-1451.

34. Sanadi AR, Caulfield DF, Rowell RM. Additives - Reinforcing Polypropylene with Natural Fibers. Plastics Engineering 1994; 50(4):27-28

35. Feng D, Caulfield DF, Sanadi AR. Effect of compatibilizer on the structure-property relationships of Kenaf-fiber/polypropylene composites. Polymer Composites 2001; 22(4):506-517.

36. Sanadi AR. Caulfield DF. Transcrystalline interphases in natural fiberPP composites: effect of coupling agent. Composite Interfaces 2000; 7(1):31-43.

37. Boyd RH. Relaxation Processes in Crystalline Polymers - Experimental Behavior - A Review. Polymer 1985; 26(3):323-347.

38. Chartoff RP. Assignment of Glass Transition. ASTM STP 1249. Philadelphia, PA, USA: ASTM Publications; 1994.

39. Wunderlich B. Assignment of the Glass Transition. ASTM STP 1249. Philadelphia, PA, USA: ASTM Publications; 1994.

40. Forest Products Laboratory. Wood-base fiber and particle panel materials. In Wood Handbook- Wood as an Engineering Material. US Government Printing Office; 1974. 